\title{
Do Medical Student On-call Reflective Reports Show Their Expressions of Emotional Intelligence? - A Qualitative Study
}

\author{
Ariyananda, P. L.
}

\begin{abstract}
Introduction: In addition to cognitive intelligence, emotional intelligence (EI) is known to play a major role in producing better doctors. When medical students are exposed to critical incidents in the hospital, it can be emotionally disturbing and such occurrences may be captured in their reflective reports. A series of reflective reports written by third year medical students, soon after exposure to such incidents, in a private medical school in Malaysia, was analysed to determine whether one could capture expression of any of the 25 competencies, inclusive of several social skills or soft skills given in the framework of Mixed Model of El by Daniel Goleman.
\end{abstract}

Methods: A convenient sample of 148 reflective reports were analysed, using grounded theory approach and discourse analysis. Expression of emotions in these reports were thematically separated into different emotional competencies which were then matched with the framework of Mixed Model of El.

Results: Reflective writing manifesting all five major divisions emotional competencies in Goleman's framework, namely; self-awareness, self-regulation, motivation, empathy, and social skills were found in many of the reports. Excerpts from of five different reflective reports (only the contextual component without the students' reflection) manifesting each of these five major divisions of emotional competencies were given as triggers for focus group discussions and three out of the five showed close triangulation.

Conclusion: Reflective reports seem to be useful to detect expression of El. In addition, reflective reports seem to have a potential use as a tool to nurture El in medical students.

Key words: Emotional intelligence, Emotional competence, Soft skills, Reflective reports

\section{Introduction}

Some doctors have had bright academic careers, but are not sought after by patients or do not get on well with their colleagues. Academic excellence alone cannot gain respect or win the hearts of patients or make good team players. In addition to cognitive intelligence, what makes a good doctor, includes an important attribute called emotional intelligence (EI).

Professor P. L. Ariyananda

Department of Internal Medicine, Clinical Campus, International Medical University, Jalan Rasah, Seremban 70300, Malaysia.

Email: ariyananda@imu.edu.my
El is known to nurture professional excellence (Cherry et al., 2012). In this study the author has adopted the 'Mixed model' of El described by Daniel Goleman (Tables $1 \& 2$ ) to measure the expression of $\mathrm{El}$ in students' reflective reports (Goleman, 1998).

Professionalism and communication skills are essential qualities of a good doctor and these attributes need EI (GMC, Good Medical Practice, 2013). Many social skills can be considered to be soft skills. Soft skills collectively or individually, manifest as good professional conduct among doctors. These include leadership skills, trustworthiness, altruism, empathy, respecting others, interpersonal relationships, communication

DOI: http://doi.org/10.4038/seajme.v14i1.232

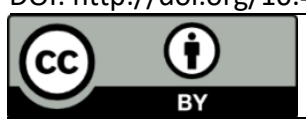

31

(c) SEAJME. This is an Open Access article distributed under the terms of the Creative Commons Attribution License (http://creativecommons.org/licenses/by/4.0/), which permits unrestricted use, distribution, and reproduction in any medium, provided the original author and source are credited 
skills, problem solving skills, ability to work under pressure, ability to deal with ambiguities and complex issues, ability to be a team player, to mention a few (GMC, Good Medical Practice, 2013). Soft skills are also known as interpersonal skills or people skills or social skills. Soft skills are mainly driven by El rather than by cognitive intelligence. Soft skills are personal attributes that enhance an individual's interactions, job performance and career prospects (Goleman, 1998). Soft skills help physicians to become more sensitive, smarter, sharper as well as more effective; and as doctors we need to strive to develop it. In the context of healthcare, unlike hard skills which are about a doctor's skill set and the ability to perform a certain type of task or activity, soft skills relate to his or her ability to interact effectively with patients, care-takers, public, members of the healthcare team, medical administrators, and sometimes with policy makers, in matters concerning their work, both in and outside the hospital (GMC, Good Medical Practice, 2013). As El is very important to be a better doctor, I hypothesized that medical students should strive to nurture emotional competence from experiences in their training environment. As their trainers and mentors, we expect such experiences in their training environment to be an initial step before becoming emotionally competent.

Table 1: Personal Competence

\begin{tabular}{|c|c|c|}
\hline Divisions of El & Subdivisions of El & Competencies in EI \\
\hline \multirow{6}{*}{$\begin{array}{l}\text { Personal } \\
\text { Competence } \\
\text { (Personal } \\
\text { leadership \& } \\
\text { personal } \\
\text { management. It } \\
\text { means doing the } \\
\text { right thing \& doing } \\
\text { it right) }\end{array}$} & Self-awareness & $\begin{array}{l}\text { Emotional awareness (It is about how emotions shape } \\
\text { what we perceive, think \& do) } \\
\text { Accurate self-assessment (Knowing one's strengths \& } \\
\text { weaknesses) }\end{array}$ \\
\hline & $\begin{array}{l}\text { (Ability to think about our own } \\
\text { thought processes) }\end{array}$ & $\begin{array}{l}\text { Self-confidence (Courage that comes from certainties of } \\
\text { our own capabilities, values \& goals) }\end{array}$ \\
\hline & $\begin{array}{l}\text { Self-regulation } \\
\text { (Ability to handle our } \\
\text { emotions so that they can } \\
\text { facilitate rather than interfere } \\
\text { with the task at hand) }\end{array}$ & $\begin{array}{l}\text { Self-control (Keeping destructive emotions \& impulses in } \\
\text { check) } \\
\text { Trustworthiness (Maintaining standards of honesty \& } \\
\text { integrity) } \\
\text { Conscientiousness (Ability to take the responsibility for } \\
\text { personal performance) } \\
\text { Innovation (Being comfortable with novel ideas, } \\
\text { approaches \& new information) } \\
\text { Adaptability (Flexibility in handling change) }\end{array}$ \\
\hline & & $\begin{array}{l}\text { Achievement drive (Successful achievement of something } \\
\& \text { striving for standards of excellence) }\end{array}$ \\
\hline & $\begin{array}{l}\text { Motivation } \\
\text { (Willingness to do things) }\end{array}$ & $\begin{array}{l}\text { Commitment (Aligning with the goals of the group or } \\
\text { organization.) } \\
\text { Initiative (Make things happen. Willingness to seize } \\
\text { opportunities. Go beyond expectations. Cut the red tape) }\end{array}$ \\
\hline & & Optimism (Belief that the best outcome will occur) \\
\hline
\end{tabular}

Adapted from Goleman, D. (1998) Working with Emotional Intelligence. New York: Bantam 
Table 2: Social competence

\begin{tabular}{|c|c|c|}
\hline Divisions of El & Subdivisions of El & Competencies in El \\
\hline \multirow{13}{*}{$\begin{array}{l}\text { Social } \\
\text { Competence } \\
\text { (How do we } \\
\text { handle } \\
\text { relationships?) }\end{array}$} & \multirow{5}{*}{$\begin{array}{l}\text { Empathy } \\
\text { (Ability to imagine how } \\
\text { another person is feeling, to } \\
\text { understand his/her } \\
\text { emotions.) }\end{array}$} & $\begin{array}{l}\text { Understanding others (Sensing others. It does not mean we } \\
\text { agree with them. Listen well. Most listen with an intention of } \\
\text { giving an answer) }\end{array}$ \\
\hline & & $\begin{array}{l}\text { Developing others (Mentoring. Talk of strengths \& } \\
\text { weaknesses) }\end{array}$ \\
\hline & & $\begin{array}{l}\text { Service orientation (Understand customer's needs and } \\
\text { match them to services and needs) }\end{array}$ \\
\hline & & $\begin{array}{l}\text { Leveraging diversity (Avoid stereotyping \& respect people } \\
\text { from different backgrounds) }\end{array}$ \\
\hline & & $\begin{array}{l}\text { Political awareness (Ability read social and political currents, } \\
\text { and the power relationships within the organization) }\end{array}$ \\
\hline & \multirow{8}{*}{$\begin{array}{l}\text { Social Skills } \\
\text { (People skills) }\end{array}$} & $\begin{array}{l}\text { Influence } \\
\text { (Wielding effective tactics for persuasion) }\end{array}$ \\
\hline & & $\begin{array}{l}\text { Communication } \\
\text { (Listening, opening \& sending convincing messages) }\end{array}$ \\
\hline & & $\begin{array}{l}\text { Conflict management } \\
\text { (Negotiating and resolving disagreements) }\end{array}$ \\
\hline & & $\begin{array}{l}\text { Leadership skills } \\
\text { (Inspiring \& guiding individuals \& groups) }\end{array}$ \\
\hline & & $\begin{array}{l}\text { Change catalyst } \\
\text { (Initiating \& managing change) }\end{array}$ \\
\hline & & $\begin{array}{l}\text { Collaboration \& cooperation } \\
\text { (Working with others towards shared goals) }\end{array}$ \\
\hline & & $\begin{array}{l}\text { Team capabilities } \\
\text { (Creating group synergy in pursing collective goals) }\end{array}$ \\
\hline & & $\begin{array}{l}\text { Building bonds } \\
\text { (Nurturing instrumental relationships) }\end{array}$ \\
\hline
\end{tabular}

Adapted from Goleman, D. (1998) Working with Emotional Intelligence. New York: Bantam Books

\section{Methods}

\section{Hypothesis}

The 'Mixed model' described by Daniel Goleman is the most widely used model of El and its framework is based on emotional competencies that fall into two major divisions personal and social competencies. Goleman further divides personal competencies into selfawareness, self-regulation, and motivation; and social competencies into empathy, and social skills (Tables 1 \& 2). As El enshrines both intrapersonal and inter-personal intelligence, it is also called 'Personal Intelligence'.
In order to find out whether nurturing of $\mathrm{El}$ occurs in our clinical training environment, I undertook a 'Grounded Theory' approach to study and analyse reflective reports which are expected to be based on their experiences and emotional responses to critical incidents that they have been exposed during their on-call sessions (Strauss \& Cobin, 1998). In this study, an attempt was made to link and match student's emotional experiences/responses on their reflective reports to items on the matrix of competencies in $\mathrm{El}$ as given in the 'Mixedmodel' of El, by Goleman, (Tables 1 \& 2). The audit trail of the study is given below. 


\section{Ethical clearance}

Informed consent was obtained from the students who wrote reflective reports and participated in focus group discussions and the approval was given by the Institutional Review Board (Project ID No.: IMU 388/2017) to analyse and publish narratives and reflections after anonymization.

\section{Study setting and sample selection}

The study was conducted in the Clinical Campus of the International Medical University (IMU) which is located in Seremban within the state of Negeri Sembilan of Malaysia. IMU MBBS degree program which is of 5-years' duration with 10 semesters, is entirely taught in English. During the Foundation Module, students are taught on how to write reflective reports, and their reflective reports are assessed during formative assessments in Semesters 1, 2 and 5 [Sow, 2010]. In Phase II, beginning in the sixth semester, medical students go through a 21-week rotation that includes 7 weeks of clinical postings each, in Family Medicine, Internal Medicine, and Surgery (IMU of Malaysia, Student Information, 2018). During the Internal Medicine Posting, each student is expected to write two reflective reports in English, around of approximately 500 words, regarding critical incidents that they have been exposed to, during their evening oncall sessions, within 24 hours for submission to their mentor, online. A pilot study, analyzing of 148 consecutive reflective reports (convenient sampling) of author's mentees that were submitted during the Internal Medicine Posting, was carried out. Data collected from May 2013 to August 2017, were analysed.

\section{Data collection and analysis}

Whether medical students would manifest their expressions of competencies in El was looked into by analysing 148 reflective reports. The data were analysed through a process of discourse analysis (Potter \& Wetherell, 1987). All reflective reports were read carefully, coded into groups, and relevant memos were made. The initial part of all reflective reports included narrations which defined the situation or the context to some extent and in some reports, the latter part included the student's reflections. These reflections helped to complete the contextualization as well. Discourse analysis helped to separate reflections into various themes (thematic analysis) that would align with competencies given in Goleman's Mixed Model of El.

\section{Triangulation}

Triangulation of data collected by discourse analysis was done with focus group discussions. Focus group discussion was done with eight different students from Semester 6 who were of the same maturity, belonging to the cohort of August 2017 - February 2018, whose reflective reports had not been included in the study sample. A reflective report each that matched the main five subdivisions of $\mathrm{EI}$ competencies (self-awareness, self-regulation, motivation, empathy and social skills) on analysis was selected from the study sample. These five reports without the emotional reactions (truncated version giving only an excerpt of the narration defining the context without the reflections) written by the students were taken up for focus group discussion, handling one scenario at a time for a period of 5 - 10 minutes. Immediately before inducting the focus group discussion, students were given the script containing excerpts of narrations (truncated version) of the reflective report. Along with it, the following trigger to initiate a discussion too, was provided: 'The narration given to you can be thought provoking. Please read this script and discuss among yourselves important issues that you would consider in case you have a similar experience'. The discussion that ensued was recorded, and later played back for analysis.

\section{Data saturation}

In qualitative data analysis, it is required to question whether the sample was adequate to reach data adequacy. When analyzing data to align with the framework given in Goleman's Mixed Model of El (Tables 1 \& 2) on the basis of 'grounded theory', the number of emotional competencies available were limited to 25 (Tables 1 and 2). Having explored all possible links in reflective reports for alignment, there was no data to suggest expression of some more emotional competencies (Table 3), showing that a point of redundancy has reached. Such an approach seems to be acceptable to some workers in qualitative research (Morse, 1995). However, Glaser recommends that data collection and analysis should be carried forward until a point of saturation is reached (Glaser, 2007).

\section{Member check}

A 'member check' was not performed as getting back to authors of reflective reports was considered irrelevant on grounds that validity of their emotional response is situational, and only 
credible when their comments are 'nascent', soon after the encounter.

\section{Results}

Analysis of 148 reflective reports using Goleman's Mixed-model of El revealed reflections that aligned with many of the competencies given (Table 3 ). Some reports contained reflections on more than one competency in El. Unlike in quantitative studies, what is crucial in qualitative studies is not the number of data recurrences, but the richness of data brought in by detailed description (Glaser, 2007). Representative excerpts from reflective reports manifesting each of the five broader competencies mentioned are given below. Accounts given under those emotional competencies includes narratives (given in italics within quotes) of critical incidents that students have lived through, followed by comments from the author and views of the medical students in the focus group, with some relevant references.

Table 3: Breakdown of expression of different competencies in EI manifesting in reflective reports*

\begin{tabular}{|c|c|c|c|}
\hline Divisions of El & Subdivisions of El & Competencies in El & $\begin{array}{c}\text { No. reports with EI } \\
\text { competencies }^{\star}\end{array}$ \\
\hline \multirow{12}{*}{ Personal competence } & \multirow{3}{*}{ Self-awareness } & Emotional awareness & 1 \\
\hline & & Accurate self-assessment & 15 \\
\hline & & Self-confidence & 9 \\
\hline & \multirow{5}{*}{ Self-regulation } & Self-control & 8 \\
\hline & & Trustworthiness & - \\
\hline & & Conscientiousness & 1 \\
\hline & & Innovation & - \\
\hline & & Adaptability & 3 \\
\hline & \multirow{4}{*}{ Motivation } & Achievement drive & 3 \\
\hline & & Commitment & 14 \\
\hline & & Initiative & 3 \\
\hline & & Optimism & - \\
\hline \multirow{13}{*}{ Social competence } & \multirow{5}{*}{ Empathy } & Understanding others & 39 \\
\hline & & Developing others & - \\
\hline & & Service orientation & 4 \\
\hline & & Leveraging diversity & 2 \\
\hline & & Political awareness & - \\
\hline & \multirow{8}{*}{ Social Skills } & Influence & - \\
\hline & & Communication & 40 \\
\hline & & Conflict management & 2 \\
\hline & & Leadership skills & - \\
\hline & & Change catalyst & - \\
\hline & & Collaboration \& cooperation & - \\
\hline & & Team capabilities & 14 \\
\hline & & Building bonds & 7 \\
\hline
\end{tabular}

148 reports were analysed. Figures in the table cannot be expressed as percentages as some reflective reports expressed more than one competency in El. Reflections around some competencies of El were more evident; and those include self-awareness (accurate self-assessment), self-regulation (self-control), motivation (commitment), empathy (understanding others) and social skills (communication skills). 


\section{Self-awareness:}

Accurate self-assessment: Reflections given below describe emotional perceptions that ran through the student's mind during an unfamiliar experience in the hospital.

'While doing the venipuncture, I realized that I was not as confident as when I practiced in the Clinical Skills Unit (CSU). I appeared nervous and my hand was shaking. I think you should practice on venipuncture skills more times in the CSU, and then proceed to do it on real patients'

(Reflective report \#82). Student is not yet ready to perform a venipuncture. He realizes that he needs more practice. The focus group was given the same scenario (truncated scenario \#82) and their discussion revolved around the need to appear self-confident and courageous when facing a similar situation with the performer (student) being cognizant of his or her limits. The student who wrote the reflective report as well as those in the focus group were on the same page and are talking about accurate self-assessment - it is about knowing one's strengths and weaknesses (Table 1), an essential skill for health care personnel.

\section{Self-regulation - self-control:}

A student having worked in the Emergency Department reflects as follows:

I have also learned that as doctors, especially in the Emergency Department, we have to be capable to think clearly under pressure and be emotionally detached from the situation in order to give the best solution for the patient'

(\#84), Emotional competency with respect to self-control involves keeping a check on destructive emotions and impulses (Table 1). The focus group was given the same scenario (truncated scenario \#84) and the group was in resonance saying that it will be useful to get exposed to medical emergencies as students, as repeated exposures would build confidence without losing self-control and getting panicked when handling such situations later, as doctors.

\section{Motivation - Commitment:}

'As a doctor in the future, I will have to manage patients in a ward at night during the on-call. Therefore, I have to be very independent, responsible and competent to do my job well'
(\#41), commented another student. $\mathrm{He}$ is committed and ready to make sacrifices to meet the goal of becoming an effective and efficient doctor. When people are motivated (express willingness to do things - table 1) they set challenging goals and take calculated risks. Their drive is goal oriented and they learn to improve the performance with time. The focus group that discussed the same scenario (truncated scenario \#41) was highly engrossed in a discussion where they felt a patient mentioned by the student in the report should be empathized as they were carried away by the suffering that was described in the report. They did not mention about motivation or resonate with what was in the written reflection.

\section{Empathy:}

Understanding others: In another report student is reflecting on an incident where an old diabetic patient with extensive foot ulcers who was kept nil orally awaiting debridement was demanding water to quench her thirst.

'Whether it be a nurse or a doctor, we should always do what we can do to make the patient feel better. By tapping on the shoulder when they cry, by helping to call their family members, by clearing doubts in their minds - if those actions help them, why not do so'

(\#59) In this student reflection, the incident seems to have invoked empathy. Although the focus group was given the same scenario (truncated scenario \#59), their discussion did not express feelings of empathy, but discussants agreed that the patient should be more informed of her situation - such as the fact that she cannot have a drink, as she is kept fasting for surgery. This student does not seem to have such barriers and seem to recognize the need for empathy in his reflections. Although empathy generally means an emotional state where one is moved by some others emotions; as doctors we are expected to practice in a detached manner by correctly acknowledging the emotional state of another without actually experiencing it. Neutral empathy is a role where the physicians do what needs to be done without feelings of guilt, regret or other related emotions (Blumgart, 1964). To master the art of 'neutral empathy', students and young doctors should engage in empathetic communication to make their care seem more natural. Qualities expected to facilitate more successful relationships with empathy are known to be related to El (Schutte et al., 2001). 


\section{Social skills- Communication skills:}

In the hospital doctors and medical students examine patients with the curtains drawn and chaperons by their sides. However, I feel that drawing curtains might be just enough to prevent exposure of patient's bodies but the conversations can be overheard by others as the distances between beds are within an earshot. Hence, if sensitive issues were to be discussed, it is better to conduct the conversation within a closed room'

(\#72), Student realises that patient's confidentiality needs to be respected as most of the communications can be considered as 'privileged information'. The focus group that was given the truncated scenario \#72, echoed the same sentiments. Studies have shown that confidentially breaches occur due poor infrastructure facilities, as in this situation (Beltran-Aroca et al., 2016). What is more important to note is that the student realizes that there is a lapse in communications; and such cognizance can be considered to be driven by El.

\section{Discussion}

The level of emotional competence varies depending on the task, individual and the context, and it is hard to quantify. Students' reflections on critical incidents that were captured in writing are on some incidents they have experienced when interacting with patients and their carers. Reporting and reflecting on critical incidents seems to have an educational value for medical students (Branch, 2005). These are useful for developing positive attitudes and behaviours as well as values that are essential to be a good professional. How students feel about critical incidents can be in written as reflective reports which can be nascent and unpolished accounts of their experience and perceptions without being diluted by afterthoughts or opinions. In addition, such reflective reports embody a component of experiential learning (Kolb, 1984). Such reflective reports also represent sensitivity and recognition of moral issues as well as indications to stand-up regarding one's own beliefs.

As most adults, medical students too need to walk through new experiences and learn by reflection. 'Reflection' is a metacognitive process and has been defined by Boud et al., (1985) as 'a generic term for those intellectual and affective activities in which individuals engage to explore their experiences in order to lead to a new understanding and appreciation'. Reflective practice occurs when students exercise reflection in the context of working with ill-defined experiences or problems in professional practice (Sanders, 2009). Reflective practice seems to facilitate development of El.

\section{Limitations}

There are few limitations to the study.

1. Single authorship: Whether an element of subjectivity and bias may have occurred as the study was done only by one person is debatable, as appraisers of qualitative research increasingly seek to assess the competence and reflexivity of a single researcher than confirm that the findings were checked by someone else (Greenhalgh, 2010). As discourse analysis focuses not only on the text but also on its construction within a context - with inclusion of both historical and political connotations - single author reflexivity becomes more meaningful. The author has 45 years of experience as a doctor and 35 years of teaching experience in Internal Medicine for medical undergraduates and postgraduates and this background helped to enrich his meticulous ethnographical approach and reflexivity, when data were analysed.

2. Reflective reports were limited to 500 words. This may have hindered documentation of emotional engagement due to lack of fluency in expressing such situations in a more explicit and detailed manner.

3. There is some variation with regards to training and maturity of students at the time the reflective report was written, depending on whether Internal Medicine posting was placed first, second or last in the clinical rotation during the Semester; and it might have contributed to intra-sample variation.

\section{Conclusion}

The emotional experience students go through during exposure to critical incidents can condition the way they would perceive and respond when they face similar clinical scenarios during their practice as doctors in the future (Brady, 2002). According to the transformative learning theory, adult learning can be triggered by disturbing dilemmas such as those gone through by students in this study. 
Transformational learning that is seen in this study involves change in existing beliefs and thought patterns through the use of discourse and critical reflection (Mezirow, 1994).

The study revealed that students have been exposed to a variety of clinical situations which made them react either with positive or negative emotions. In the foregoing account, many of them have pledged to change their behaviour; and this seems to be an adaptive response to suit their future careers as doctors. Such expressions can be considered as evidence of expression of $\mathrm{El}$ that would help them to function as better doctors in years to come. As these reflective reports do not contribute to student assessment, their reflections can be considered to be genuine expression of what goes through their mind, invoking the power of $\mathrm{El}$ to rationalise emotionally disturbing dilemmas, that they come across in the clinical learning environment.

\section{Implications of this work}

Reflective reports seem to have a potential to detect expression of $\mathrm{El}$ with acquisition of emotional competence, and a prospect to nurture $\mathrm{El}$ with the help of mentor feedback. Therefore, reflective reports should be exploited for its scope as a teaching/learning tool in El. In this study, the fact that a 'thick description' is available shows the potential for transferability of this hypothesis for training of other healthcare workers. Similarity in learning environment across different healthcare professions makes it even easier to recontextualize, such teaching/learning situations.

\section{Conflict of Interest}

The authors declare no conflict of interest.

\section{Acknowledgements}

I am grateful to IMU, Malaysia for permitting me to analyse student reflective reports and to Professor Sivalingam Nalliah for his insightful comments on the manuscript. The study was not funded.

\section{References}

Beltran-Aroca, C.M., Girela-Lopez, E., CollazoChao, E., Montero-Pérez-Barquero, M. \& MuñozVillanueva, M.C. (2016) Confidentiality Breaches in Clinical Practice: What Happens in Hospitals? BMC Medical Ethics, 17, 1, pp.52.
Blumgart, H. (1964) Caring for the Patient. New England Journal of Medicine. 27. pp. 449 -456.

Boud, D., Keogh, R. \& Walker, D. (1985) What is Reflection in Learning. Reflection: Turning Experience into Learning, pp.7-17.

Brady D.W., Corbie-Smith G. \& Branch W.T. Jr. (2002) "What is Important to You?" Use of Narratives to Promote Self-reflection and to Understand the Experiences of Medical Residents. Annals Internal Medicine. 137. pp. 220-223.

Branch W.T. (2005) Use of Critical Incident Reports in Medical Education. Journal of General Internal Medicine. 20. pp. 1063-1067.

Cherry, M.G., Fletcher, I., O'sullivan, H. \& Shaw, N. (2012) What Impact do Structured Educational Sessions to Increase Emotional Intelligence have on Medical Students? BEME Guide No. 17. Medical Teacher, 34, 1, pp.11-19.

General Medical Council (2013), Good Medical Practice (Online), March 2013. Available from https://www.gmc-uk.org//media/documents/good-medical-practice--english-1215_pdf-51527435.pdf [Accessed: 20/08/2019].

Glaser B.G. (2007) Remodeling Grounded Theory. Historical Social Research, Supplement. 19. pp. 47-68.

Goleman, D. (1998). Working with Emotional Intelligence. New York: Bantam Books.

Greenhalgh, T. (2010) How to Read a Paper. The Basics of Evidence-based Medicine. Oxford, England, Wiley Blackwell.

International Medical University of Malaysia Student Information, Regulation \& Code of Conduct (2018). Available from: https://elearn.imu.edu.my/mod/folder/view.php?i d=9962 [Accessed: 20/08/2019]

Kolb, DA. (1984) Experiential Learning: Experience as the Source of Learning and Development. New Jersey: Prentice Hall.

Mezirow J. (1994) Understanding Transformation theory. Adult Education Quarterly. 44, 4. pp. 222232.

Morse J.M. (1995) The Significance of Saturation. Qualitative Health Research. 5, 2. pp. $147-149$.

Potter J. \& Wetherell M. (1987) Discourse and Social Psychology, London: Sage.

Sanders J. Use of Reflection in Medical Education. (2009) AMEE Guide No. 44. Medical Teacher. 31, 8. pp. 685- 695. 
Schutte N.S., Malouff J.M., Bobik C., Coston T.D. Greeson C., Jedlicka C., Rhodes E. \& Wendorf G. (2001) Emotional Intelligence and Interpersonal Relations. The Journal of Social Psychology, pp. 141:523-536

Sow, C. F. (2010) Reflective Writing. [Online]. Available from: https://elearn.imu.edu.my/mod/folder/view.php?i $d=11266[$ Accessed: 20/08/2019].
Strauss A., \& Cobin J. (1998). Basics of Qualitative Research: Techniques and Procedures for Developing Grounded Theory, $2^{\text {nd }}$ ed. Thousand Oaks, Sage. 